Article

\title{
Tallinn Film Cluster: Realities, Expectations and Alternatives
}

DE DE GRUYTER

OPEN

INDREK IBRUS, Tallinn University, Estonia; email: ibrus@tlu.ee KÜLLIKI TAFEL-VIIA, Tallinn University, Estonia; email: ktafel@tlu.ee SILJA LASSUR, Tallinn University, Estonia; email: silja@tlu.ee ANDRES VIIA, Tallinn University, Estonia; email: viia@tlu.ee 


\section{ABSTRACT}

The article takes a close look at the entrepreneurial practices of the Estonian film industry and at how these particular practices may be understood to influence the evolution of the film production cluster in Tallinn. It asks how these processes of institutional evolution of the local film industry may be understood to influence the specific nature of audiovisual culture in contemporary Estonia. The article is based on a study that was conducted in mid 2012. The study consisted of interviews with the representatives of the local film industry, including respondents from production companies ("studios"), post-production companies and distributors. The second phase of the study was a confirmative roundtable with the select group that included the previously interviewed filmmakers and a few additional industry insiders. The key research questions were: (1) what are the existing co-operation practices between companies like and (2) considering the further evolution of the industry cluster in Tallinn, what are the companies' specific expectations and needs. The current status of the cluster's competitiveness was evaluated by using Michael Porter's model for analyzing conditions of competition (Porter's diamond). Also, development perspectives of the cluster were evaluated, considering the needs and expectations of entrepreneurs. Key results of the research were divided into two basic categories: (1) current state of clustering of AV enterprises and (2) perspectives and alternatives of further development of the AV cluster.

INTRODUCTION

Clusters of firms and other institutions that contribute to the production of culture are important in at least two ways. Firstly, as will be demonstrated below, they are expected to strengthen the industrial base of the production activities in terms of its economic rationales - i.e. will facilitate an increase in exchange dynamism and will therefore condition additional surplus value for all integrated production processes.
The enhanced dynamism and productivity is also expected to spread within the clustered industry and that is eventually expected to also spill over into related local fractions of the economy, generating economic growth in the region. Secondly, as it has been emphasised especially within the evolutionary economic approach to creative industries (see Potts and Keane 2011), in the case of creative industries such clusters have a potential to constitute the ground- 
work for a diverse and dynamic cultural milieu that provides the broader 'national innovation system' with much needed circulation of alternate ideas and reflections. That is, creative clusters also have a potential for operating as purpose driven incubators for innovative artistic thought and experiments, facilitating heightened artistic and cultural dynamism in the particular region or a city where the cluster is located in. It is due to such dual functionality of creative clusters and their impact on general societal evolution that they should be carefully studied. That is, an academic quest for evidence is in place, in order to inform the relevant policy process in Estonia and elsewhere.

The above-described rationale was also among the motivations for a study conducted in Tallinn, Estonia's capital in 2012. In more concrete terms, from the perspective of Estonia's leading institutions of the audiovisual production sector (Estonian Film Institute, Film Estonia) there was a need for research into the clustering potential in Tallinn. The latter institutions therefore commissioned a two-part study from Tallinn University's Estonian Institute for Futures Studies. The present article reports on the rationales and findings of that study. In more detail the aim of the study was to investigate the then existing realities of entrepreneurial practices in the local film industry together with their potential cluster-like relationships and other related tendencies.

Such a study of clustering in the Estonian film industry was to an extent unprecedented. The operations and practices of Estonian audiovisual content production industries have been generally studied only very little. In the last ten years the Estonian Institute of Economic Research has mapped the scope and structuring of Estonian creative industries including audiovisual content production sub-sector three times (2005, 2009, 2013) ${ }^{1}$ by mainly combining all the existing statistical and market data. In 2007, a consultancy called Peacefulfish conducted a cost analysis of the clustering

1 See http://www.ki.ee/ potential of the Estonian film industry. The entrepreneurial practices within Estonian creative industries in general were investigated in 2011 (Tafel-Viia et al. 2011) in a study that focused on the growth potential of Estonian creative industries' start-ups housed in the relevant incubators in Tallinn and Tartu. One of the findings of that study was that compared to start-up companies of other subsectors of the creative industries the young micro-companies of audiovisual content production were relatively more inclined towards achieving growth and international operations. What is more, the film-sector start-ups were also more interested in moving their operations to dedicated production facilities that could then also operate as 'physical infrastructures' for the potential cluster. Our new study, presented here, expanded on these findings, the new aim was to investigate the further potential of cluster development in Tallinn, based on motivational varieties of all kinds of companies and institutions constituting the film production industry in Tallinn.

\section{OVERVIEW OF ESTONIAN FILM PRODUCTION SUB-SECTOR}

Although only limited data exists on the economic scale and scope of the Estonian film industry, still the following sections are aimed to contextualize our study by introducing some of the basic economic data on the Estonian film sector. Most of the relevant information is taken from a recent mapping of the Estonian creative industries conducted by the Estonian Institute of Economic Research (2013).

\section{Incomes}

There were 363 companies of audiovisual content production (the statistic does not separate between film and television production) officially registered in Estonia in 2011 (138 companies more than 4 years earlier, in 2007). The number of people employed in the sub-sector in 2011 was 1092. The gross income of the subsector was $€ 50.7 \mathrm{MM}$. Income from sales was €43.7 $\mathrm{MM}$, constituting $86.3 \%$ of gross income. Public funding for film production consti- 
tuted an additional 12.3\% (€6.2 MM), local governments contributed €27 000 (0.1\%). Lastly, production support from international funds was 1.3\% (€700 000). Gross profit of audiovisual (AV)-sector companies was $€ 3.5 \mathrm{MM}$ - constituting $0.08 \%$ of Estonia's private sector gross profit. At the same time, AV-sector turnover constituted $0.12 \%$ of private sector turnover in 2011 - the difference pointing to comparatively lower productivity in audiovisual content production in relation to the rest of the economy.

When it comes to public funding, the main funding agency is the Estonian Film Institute (before 2013 known as the Estonian Film Foundation) that distributes money that mostly comes from the state budget - in $2011 € 3.1 \mathrm{MM}$ for film production support. The second biggest contributor is the Estonian Cultural Endowment that gets its funds mostly as a share of Estonian alcohol, tobacco and gambling taxes - in 2011 contributed to film-related activities (not only production, but also support for festivals, grants for travels, etc.) in the amount of $€ 1,4 \mathrm{MM}$. The rest of state funding comes straight from the budget of the Ministry of Culture ( $€ 523000$ in 2011) together with some appropriations by the Council of Gambling Tax (€12 000 in 2011). The main source of business revenues is the production of TV commercials and other TV content. Incomes from ticket sales, VOD (video on demand) services and DVD or license sales may vary, but is not always insignificant. Unfortunately, especially the latter three are currently unknown variables - there is no data available to make justified assessments of their scales.

\section{Structure}

As elsewhere, the film industry is divided into the following sub-divisions: production ("studios"), post-production, distribution, and cinemas. Out of these 198 companies and 390 people were involved in producing "films"; 64 companies (155 people) were busy with producing TV programmes; 63 companies (160 people) were employed in post-production; 15 companies (25 people) were doing distribution; 7 companies and 234 people were involved with screening films (operating cinemas). Turnovers were highest in screening business, productivity in post-production.

\section{Films produced}

187 films were produced in 2011. 25 of these were "cinematographic films", including 13 "feature length" films, and 162 "video films". The 25 "cinematographic films" could be suggested to to be part of a standard film industry value chain - i.e. films being screened in cinemas and sold on DVD/VOD. The other "video films" were either advertising, promotional films or various productions for TV.

\section{Audience}

The size of home market has been in Estonia as problematically tiny as elsewhere in Europe. In 2011, Estonian films were watched in cinemas by 172290 people, which makes $7 \%$ of all film consumption in cinemas. In 2012, the numbers were respectively 195488 people and $7.6 \%$. The most viewed Estonian film in cinemas was "Lotte ja kuukivi saladus/ Lotte and the Moonstone Secret" with 63800 viewers - which took it to 6th place in the "most viewings" ranking list in Estonia. A year later the most viewed Estonian film was "Seenelkäik/Mushrooming" with 73700 viewers and 4th place in the ranking. One of the major challenges limiting the potential growth of these numbers is the small number of regularly operating cinemas in the country. There was only 12 cinemas that operated in the three biggest towns, elsewhere films were shown publically only irregularly - on semi-improvised screens and as secondary activities in museums, theatres and other public buildings. The 12 cinemas in operation had altogether 74 screens, 15 of them digital (18 in 2012). The small number of digital screens undermines further efforts to strengthen the home market scale.

With an approximate one-year delay, most films also make it to local TV channels where the audience numbers are normally multiplied by tens, however the income to production companies from these local TV license sales is normally financially insignificant. 
International reach

There is no data comprehensive enough on film-sector exports (both license sales and services), but when it comes to international marketing efforts there is information of 9 "market screenings" at Cannes and Berlin film festivals ("The Graveyard Keeper's Daughter", "A Friend of Mine", "Letters to Angel", "Rattrap", "Idiot", "Farts of Fury", "Cubaton"). When it comes to festival screenings 79 films were screened at international festivals in 2011 (344 screenings altogether) and 185 films in 2012.

\section{Organisation and education}

There is a variety of institutions that shape, delimit and drive the film industry in Estonia. The Estonian Film Institute as the main funding agency, which also takes care of some of its general development work (marketing, heritage digitisation, etc.) is normally perceived as the driver with clout when it comes to local production issues. Film Estonia is the institution responsible for marketing Estonia's film production services and also manages a post-production facility as a rental service. When it comes to self-organisation of professionals and the industry then these processes are very fragmented - there is a weak all-encompassing Estonian Filmmakers' Union with mostly older generation filmmakers as members and a multitude of smaller associations for producers, directors, DOPs (directors of photography), studios, documentary filmmakers, animators, etc. Such structuring keeps the industry fragmented and hinders its further integration, including potential clustering. An institution that may contribute towards integrating the industry is the regionally vital Tallinn University Baltic Film and Media School (BFM) - with its new purpose-built house in downtown Tallinn that also accommodates two studios, as well as the post-production facility of Film Estonia. BFM has a potential to function as a space that brings the industry professionals and its offspring together. When it comes to industry evolution BFM with its more than 400 registered students is important in terms providing a trained workforce.

\section{CLUSTERS IN \\ CREATIVE INDUSTRIES}

Generally, economic clusters are considered to be agglomerations of interconnected enterprises and organisations of an industry that are all located in the same geographical area (Porter 1998). There are two main schools of thought that provide the conceptualisation of a cluster. Firstly, an economic approach that departs from a point of view of economic statistics defines a cluster as an agglomeration of enterprises in a certain territorial unit and focuses on how the links between enterprises could be used more efficiently. Alternatively, social scientists and geographers tend to postulate sets of certain minimum requirements (concerning the types of relationships between enterprises and the intensity of communication between them), the existence of which justifies the application of the term 'cluster'.

These disciplinarily different approaches to cluster conceptualisation have not been mutually exclusive. Cluster concept has widened as well as diversified over time. Several (additional) characteristics, including deeper understanding of the actors and their activity patterns, spectrum of goals of the cluster, different types of partnerships between cluster participants, etc. have emerged as analytically relevant when explaining the development of clusters. Gordon and McCann (2000) have distinguished three different types of cluster models that historically emerged at different points in time. The first is the classic model of agglomeration based on either local resources, demand or other advantages offered by the local economic environment (Marshall 1925; Hoover 1948); the second is the neo-classical model that focuses on value chains based on direct economic links between enterprises (Moses 1958; McCann 1995); and the third is postindustrial social network or club model based on social relationships and trust between the members of a cluster (Harrison 1992; Granovetter 1985). These different approaches have also been somewhat convergent; we may recognize that cluster models based purely on economic factors 
have evolved over time to include socio-cultural dimensions.

The researchers studying the specific nature of creative industries' clusters (e.g. Pratt 2004; Roodhouse 2006; Davis et al. 2009; Evans 2009a) tend to suggest that compared to more conventional clusters the objectives of creative clusters are connected to either social or cultural goals in addition to economic and growth targets. Therefore, we propose that in order to explore the evolution of the film cluster in Tallinn we need to analyse cluster characteristics and the related developments on the one hand, and the specific peculiarities of actors (enterprises) in audio-visual sector in particular, on the other hand. What is more, in this article we take the approach that an agglomeration of enterprises and organisations located in a common region is only a potential cluster. We proceed from an understanding that, for the formation of an actual cluster to take place, two parallel processes have to amplify each other: first, economic cooperation between enterprises and, secondly, communication between the key individuals of those companies that creates synergy and establish trust.

Proceeding from the need to investigate the relationships that constitute and shape the modern creative clusters we propose that the specific networking dynamics in such clusters and therefore the nature and evolutionary dynamics of clusters are also affected by an ongoing socio-cultural circumstance, i.e. the evolution of the "network society” (Castells 1996; van Dijk 2006). What this concept refers to is that most societal relationships tend to be structured by the Internet as an infrastructure that conditions people to form networks for almost all activities regardless of whether it includes production, consumption or experiencing. The paradox of networks lies in their strong ties to a location but also in their irreversible connection to the largest of global networks. This causes all networks to function at their most efficient on the local level while being more or less directly influenced by international dynamics, thus supporting individuals in making international contacts as well as fostering the export activities of enterprises. In terms of the development of a cluster, this signifies an opportunity for more efficient local interactions and coordination of activities, but also for more direct links with related dynamics globally.

In terms of the structure of the cultural labour market, one of the main characteristics of a network society is the increasing individuation of the society, which may strengthen the standing of individuals in labour relations, production processes and industry structures. Networks condition individuation as the "nodes" of networks are now constituted by the individuals rather than different communities or institutions. Managing the flow of information in a network society is increasingly the responsibility of individuals, and consequently, the same applies to labour relations and creative activities. In addition, the decreasing cost of technologies of media production must be mentioned since this allows for smaller production units that replace the huge studios and other "industrial" production facilities of the past. Additionally, the increasing specialisation within the knowledge-based industries must be taken into account as this has led to the evolving complexity within creative industries - where a specific service can often be acquired from only a very small set of adequately skilled individuals or enterprises. Also the dynamics characterising most media markets - that these tend to evolve towards oligopolistic structures - may often condition that the sheer majority of companies in the audiovisual sector is constituted by microsized independents. Resulting from all the aforementioned causes, the audio-visual sector of the network age consists increasingly of micro-enterprises with only a few employees.

One of the consequences of this for creative entrepreneurs is that planning their career and securing an income entails a greater risk. Work is becoming unsteady, irregular, temporary and project-based; often, individuals work part-time for several companies fulfilling various roles. In this context, individuals always have less 
influence and power than larger communities to secure their jobs. At the same time, Gill (2007) has pointed out a paradox that creative individuals value this situation as one that allows for more freedom and independence. However, it must be understood that the individuation of a network society is not of the isolating kind but the trend is instead towards a "hyper-social society". "Networking" or the conscious creation and managing of contacts is developing into the main method of managing risks involved in individuation. Gill has demonstrated that conscious and purposeful networking strategies are characteristic of "independents" in a wide array of creative industries.

As several researchers (Banks et al. 2000; Deuze 2007) have demonstrated, the central factor of such networking activities is trust between creative individuals. As mutual trust and habits of cooperation develop, especially when the often projectbased practices of creative industries is taken into account, we see the same or similar teams working on a string of projects. Organising work in such a manner is very characteristic of producing audiovisual content. The fact that relationships in creative industries may directly condition how work is organised points to the question of correlation between the social relationships of individuals and the exchange relationships between enterprises in the sector. As explained above, creative sectors are characterised by the importance of both of these aspects: horizontal relationships between people and vertical relationships (value and supply chains) between enterprises. However, in the case of micro-enterprises, these verticals can almost overlap; this is important because, as previously demonstrated, the Estonian film industry mainly consists of micro-enterprises. In other words, both economic and social dynamics are behind the development of a cluster in the film industry. On the one hand, the economies of scope logic may lead to the formation of clusters - the need to decrease production costs while making production more efficient, the opportunity to discover synergy between enterprises and to grow together. On the other hand, it is the trust between individuals and the opportunity for like-minded people to create something together.

The former aspect (overlapping of human and business relationships) is connected to the statements about the wider horizontalisation of relationships in the creative sector. Wirtz (2001), among others has suggested to that it is increasingly justified to talk about the complexity of "value nets" instead of linear value chains. "Co-opetition" is another well-known concept, which refers to the fact that cooperation and competition might not be mutually exclusive in modern creative sectors. These concepts must simultaneously refer to the increasing complexity of value chains and business models during the Internet age (plurality of parallel business models, their mutability and therefore the unclear bargaining power of enterprises) and also to the horizontalising effect that the Internet is often considered to have.

Based on this logic of increasing ambiguity of relationships between micro-enterprises and on the related market uncertainties, Potts et al. (2008) have proposed a new concept for describing the modern creative industries. It is called "social network markets". This concept recognises that in the case of creative industries we must look beyond the "industry"-centred interpretation. The central characteristic of creative industry is not the inputs and outputs of a production process but first and foremost the specifics of markets or more precisely their ambiguity. The nature, value and ultimately the prices of cultural products are always unknown variables to consumers and to a certain extent also to the producers themselves and therefore difficult to determine. Resultingly, the economic and financial relations are not easily stabilised in creative industries and there is therefore also no place for price competition. This ambiguity is alleviated by social networks that link both producers and consumers. As was previously mentioned, social networks are characterised by trust between their members and a certain similarity in value 
systems. Therefore, the central factors on a market full of ambiguities are the choices of other trusted network members and recommendations for consumption made on the basis thereof. In the creative industries of the networking age, decisions to consume or produce are made primarily on the basis of feedback from networks.

Based on Potts and his colleagues, contemporary creative industries should not be interpreted simply as subsidised arts or the "cultural industry" or "creative businesses" but as a large number of specific goods and services that are always "new" and without a clear "use value". In order to determine their value, network participants must rely on the filtering capability of their social networks. Due to this, the adjusted definition of creative industries is as follows: "The set of agents in a market characterized by adoption of novel ideas within social networks for production and consumption" (Potts et al. 2008). The arts are always striving towards new representations and are therefore valuable for the society and economy due to their ability to generate new meanings and ideas; therefore, the communicative dynamics of networks help to filter out the most valuable. Therefore, the networks of the creative sector can be seen as coordinating mechanisms for innovation processes. In this context the evolution and the specific nature of creative clusters as networking hubs can be considered significant in terms of generating innovations with economic value as well as for facilitating broader cultural dynamics in a particular culture/society. What is more, it is the dynamics of internet-mediated 'social network markets' that can be suggested to facilitate the increasing emergence of 'virtual clusters' in the creative industries.

Due to the dual functions of not only generating economic growth, but also cultural dynamism, creative clusters are not usually formed in the same manner as generic industrial clusters, the agglomeration of which is often based on the strengths of the local markets or the existence of institutions that develop technologies (universities). In case of creative clusters, companies agglomerate in more organic ways as many creative projects are implemented one after another in cooperation among loose sets of creative individuals/micro-companies. Such clusters are therefore formed on the basis of real cooperation and existing dynamics - where there is activity, more will follow if the circumstances are right. Several studies have demonstrated that it is relatively more characteristic of creative clusters to converge in a small territory (Lazzeretti et al. 2008; Evans 2009a, b). The convergence of creative enterprises often means they are located on a single street or in the same quarter. Such spatial proximity is expected to promote intense everyday communication between creative individuals and companies. According to a widespread view, most creative clusters are de facto cultural quarters and not economic clusters as defined by Porter. Strong agglomeration is also generally characteristic to AV companies that are, pursuant to geostatistics, some of the most highly concentrated companies in Europe. Over 60\% of the enterprises have converged to a certain territory; these clusters are generally situated in capital cities and located in city centres (Boix et al. 2011). Similarly to the previously described processes, the formation of AV-industry clusters is not so much dependent on the proximity of their customers as on the higher concentration of creative individuals and, therefore, on the related socialisation opportunities in an inspiring environment. What is more, concerning the specific nature of clusters that have specialised in producing audiovisual content, Lorenzen (2007) has drawn several conclusions from his analysis of the world's (large) film clusters about the aspects that ensure sustainability. Two of these aspects also have direct relevance for small clusters in small countries and also for the discussions in this paper. The first of these is that the frequency of cinema visits and the purchasing power of the home market influence the number of films produced. Secondly, public sector policy influences the home market and the export of most film clusters.

That is, the public sector policy is an important factor influencing the development of 
film clusters. However, there is still no unambiguous data about which kind of interference of the public sector helps the clusters achieve the best results. According to a study of cluster initiatives (Sölvell 2003), it is possible to presume that interference by the public sector is more successful when a contribution is made to an existing cluster that has a relatively uniformly understood common vision about increasing its competitive edge.

In the light of the above, our study aimed to focus on the nature of the existing companies in the film industry (their practices, motives, capabilities and cooperation patterns). On the one hand, this is due to the fact that organisations and networking are one of the most important factors from the point of view of cluster development; therefore, when assessing the potential of a cluster, it is important to consider how "organic" the current cooperation of enterprises and creative individuals belonging to it is.

\section{METHODS OF DATA COLLECTION AND ANALYSIS}

The data and findings presented in this article are based on the research project carried out in 2012. The data was collected using semi-structured in-depth interviews. The interview corpus was composed on the basis of the following principles: (a) to encompass representatives from all key subfields in the local film industry including representatives of production companies ("studios"), post-production companies and distributors; and (b) to include entrepreneurs with both shorter and longer entrepreneurship experience in order to evaluate how the differences in the development stages of the company influence the attitudes towards clustering. The final corpus formed by following the "snow-ball method" (Atkinson and Flint 2004) and principle of corpus saturation - i.e. the number of respondents proves sufficient if one can observe repetitive patterns in interview discourses. Representatives of a total of 19 enterprises of the local film industry were interviewed. The interviews were made with either the owners of the companies or with their senior executives (often having both roles).

The interview schedules consisted of 57 questions divided between five sections: (1) personal profile of the entrepreneur, including educational background, social activity, previous career; (2) the motives for becoming an entrepreneur; (3) company profile, including a) organizational structure and management, b) business model such as competitiveness factors, pricing practice, profile of the target group, market position, and c) cooperation partners and forms; (4) the development perspectives of the company, including the growth patterns and strategies, activity plans, success factors; and (5) requirements from support structure, including the practice of using public sector support, the expectations towards the cluster in terms of services, location and members. Majority of the questions were open-ended; nine questions had a finite set of predetermined answers. All interviews were recorded and transcribed verbatim that resulted in 420 pages of interview texts.

The interviews were analysed using text analysis method and combining various coding practices (Hsieh 2005; Laherand 2008). Based on the grounded theory approach the main themes (problems, opportunities, strengths, etc.) related to the film industry were identified and the typology of enterprises was developed containing three following types: growth-oriented enterprises; enterprises with features of growth-orientation; and lifestyle orientation enterprises. In the following, the situation of clustering of Estonian film companies was analysed on the basis of "Porter diamond" framework (Porter 1990, 1998. 2001), which analyses the competitive advantage by using four factors: (1) factor conditions, (2) demand conditions, (3) firm strategy, structure and rivalry, and (4) related and supporting industries. Factor conditions can be seen as advantageous factors found within a country that are built upon and further developed by companies - for instance, highly skilled workforce, the presence of necessary 


\section{Factors}

Factor conditions

Firm strategy, structure and rivalry

Demand conditions

Related and supporting industries

\section{Interview topics}

a. Education and professional background of the interviewee

b. Relevant factors of location for the company

c. Actualisation of intellectual property rights

d. Entrepreneurial environment and access to finances

e. Relevant infrastructure

f. Financial incentives and entrepreneurial support from public sector

a. Description of the company (age, employees, structure, etc)

b. Description of the company's business model today and after three years

c. Competitive situation (advantages and disadvantages of the company)

d. Cooperation models, -partners, -networks

a. Demand for the company's products and/or services

b. Market orientation (home vs. foreign)

c. Factors that hinder the demand

a. Cooperation partners in related industries today and in the future

b. Reactions to the new possibilities (e.g. derived from technological developments)

TABLE 1. Interview topics related to Porter's four determinants.

Source: Study "The enterprises of the audiovisual sector - the situation and needs for clustering"; conducted by the authors. 
infrastructure, established financing mechanisms, etc. Demand conditions describe the specifics of home-market demand for the products or services of the particular industry. Firm strategy, structure and rivalry encompass factors such as how companies are organised and managed, as well as the nature of domestic rivalry. Related and supporting industries concern the presence or absence of supplier industries and other related industries. The advantage forms if these kinds of industries are closely intertwined, their actions are well coordinated, they work together for innovation and achieving cost-efficiency. The interview topics corresponding to each of the four factors are presented in Table 1.

An analysis of the four factors was used to assess the strengths and weaknesses of the competitiveness of Estonian film sector. After this the development alternatives for Estonian film cluster were identified that derive from the synthesis analysis of the Porter's factors. At this stage scenario analysis (Burmeister et al. 2002; Heijden 1996) was used that enabled the stimulation of alternative future perspectives. Eventually the most common model - the four-variant structure - was used. The four alternatives were modeled by crossing two axes that reflect the most important variables or trends relating to the studied phenomena. Our analysis proceeded in two steps. First, we identified the most divergent opinions among the interviewees, and second, singled out the areas where the biggest development opportunities were seen by the interviewees.

\section{FINDINGS: SUPPORTIVE} AND DETERRING FACTORS OF THE FILM CLUSTER IN TALLINN

Although one can find supportive and deterring aspects within each of the four of Porter's factors, it can be suggested that, overall, some of these tend to be more developed and influential than others. We introduce the findings in three parts. Firstly, we present the main supportive factors of clustering in the Estonian film sector. Secondly, we introduce the main weakness- es regarding the competitiveness of the Estonian film cluster. Thirdly, we describe the future alternatives for the Estonian film cluster. See also Figure 1 that describes our interpretation of Porter's four factors in the case of the Tallinn film cluster in more detail.

\section{Supportive factors of Estonian film cluster}

The main supportive factors of the Estonian film cluster can primarily be associated with two of Porter's factors: the 'factor conditions' and 'firm strategy, structure and rivalry'. Altogether the study identified six main aspects that speak for the formation of a competitive film cluster in Estonia. Three of these relate to the business practices of Estonian film companies. The first is the general growth orientation and international ambition of film companies. Although the landscape of Estonian film is diverse consisting of tens of micro and small companies and representing a wide spectrum of different kinds of business models and activity patterns, the results indicate that about half of the respondents have plans for expansion - to develop the organisation and increase the number of employees. Growth was normally seen to be generated by launching international operations and entering foreign markets. Even those companies that exercise lifestyle-type business models (characterised by having broader social goals, also non-monetary motivational factors and non-hierarchical structures and informal relationships) considered international orientation important, at least in the future perspective.

The second factor relates to the cooperation pattern of Estonian film companies. The results indicate that film enterprises already have tight and functioning cooperation patterns. People in the film sector are often engaged in each other's projects, even managers or owners of a film company are often involved as professionals (e.g. as DOPs, directors, editors, etc.) in the projects of other film studios. Certain differences in cooperation patterns appeared among companies with different business models. Growth-oriented companies 
(companies that intend to increase the number of employees, that consider hiring a manager or have already done so, or that have an explicit growth strategy) represent rather stable teams on their own and cooperate with other companies more on an organisational level. The networking pattern among lifestyle-oriented companies again is very variable, depending on projects and people. But irrespective of the business model, cooperation works both in terms of horizontal as well as vertical relationships. Our study confirmed what was already stated in the literature overview: the creative sectors (and potentially: clusters) are characterised by both kinds of relationships between enterprises as well as professionals.

Furthermore, the cooperation pattern of Estonian film companies also follows the co-opetition model. This indicates that cooperation and competition are not mutually exclusive, on the contrary. One day the companies may compete for external financial support, the next day they may be working together again on their next project. They are 'colleague-competitors' as one interviewee said:

...in Estonia, we only compete with other companies at the same level in the sense that whether or not they have better ideas than us, so that actually we are in the same group with these companies, so we are colleagues and competitors, it is a positive competition /.../ we tend to see people with a similar competence as competitors, they are in a similar situation, searching for interesting ideas and think in the same way, at some point we will share experiences and exchange ideas anyway; /.../So in this sense, it is sort of like challenging each other as colleagues in order to develop. [18]²

The next three supportive factors relate in different ways to Porter's 'factor conditions'. The first is the relatively well-educated and qualified human resource. The majority of the respondents have graduated from university and two third of the interviewees had obtained education in audio-visual media. However, a significantly small number of entrepreneurs have a business-related education. Entrepreneurs evaluate their competences rather high, but this applies first and foremost to their film-related professional competencies. The interviewees also expressed rather systematically that experienced and well-educated workers constitute their competitive advantage. The well-qualified workforce in Estonia's film sector can, at least partly, be related to the fact that a higher education institution offering film and media education is situated in Tallinn. Tallinn University Baltic Film and Media School can be considered a separate factor supporting the further clustering of Estonian film companies.

The clustering is also supported by the existing agglomeration of the Estonian film sector to Tallinn; moreover, most of the companies are located in the city centre or in its close neighbourhood. For most of the companies, the most decisive factors when choosing the location were: (a) good access - both for employees and clients, (b) reasonable rental price, and (c) the existence of other companies of their kind nearby, the latter associates with typical creative cluster characteristics described previously. In addition, high-speed Internet, vibration free environment, the height of the rooms and other similar factors were also considered important. Quoting the interviewee:

Where we are located is extremely important. Environment has to be such that you want be there and want to go there, that inspires you. /.../ For us it is important that we have a parking space and that around us there are other creative people from other fields of art. And that we have a fast Internet connection. And that there is no electricity disruptions or that rain would not pour in. [5] 
Deterring factors of

Estonian film cluster

The main factors deterring the further evolution of Estonian film cluster relate primarily to Porter's other two factors: first of all the 'demand conditions', but also to 'related and supporting industries'.

'Demand conditions' of Porter's diamond turned out to be the most problematic factor for the Estonian film cluster. The study revealed that small local market and low domestic demand are the most critical factors, which impede the development of film cluster. More than half of the respondents claimed that Estonian market is too small to make a living. Thus, the majority of film companies seek opportunities to orient themselves to international markets (which also explains the high rate of international ambition of Estonian film entrepreneurs). International examples of successful film clusters (although mostly outside Europe) are predominantly supported by the notable purchasing power of the domestic market. Demand for servicing foreign productions has also been rather modest. Although, several interviewed film entrepreneurs emphasised that servicing foreign productions in Estonia continues to be an underused opportunity and a line of business that has to evolve and should be promoted. The respondents saw benefits especially in getting new experiences and contacts. At the same time, Estonia is positioned rather poorly compared to other countries in attracting foreign productions to film in Estonia due to the lack of dedicated tax exemptions in Estonia.

What makes the situation difficult for us is that increasingly more countries are offering tax exemptions to foreign film producers. And as Estonia does not offer these, it may often happen that the producer chooses a studio in a country that offers these exemptions. So it may happen that won't win a competition and get some available job not because we don't measure up to quality- or pricing standard but because in our country the general envi- ronment is not favourable for film production. This is the main problem that at the moment sets us on a weak competitive position. [16]

Analysis of the demand situation also revealed one of the biggest differences among the film sector actors. There is a clear distinction between film producers and post-production companies. When the majority of film producers indicated that demand for their products or services is rather limited then all post-production companies admitted that demand for their services is high or even increasing.

The second hindering factor that suppresses the growth of domestic demand is the limited access to Estonian films by the local audiences. The small numbers of cinemas operating across the country causes this. Currently there are cinemas that operate daily in only the three largest cities in Estonia. The inability of inhabitants of smaller towns to consider cinema-going for entertainment (or enlightenment) purposes curbs the domestic demand for Estonian film. The interviewees emphasised also that VOD services are still underdeveloped. Only a few interviewed entrepreneurs indicated that a share of their income comes from digital distribution. Nevertheless, the majority of the respondents saw that several new opportunities could emerge based on the further development of new media platforms and distribution opportunities.

Certain shortages related to film production infrastructure can also be considered as barriers to clustering. The interviewees claimed that, in general, the technology and equipment necessary for film production are accessible to them. However, the absence of a proper large-scale film studio together with related services was highlighted as a growth barrier to the Estonian film sector (including to servicing foreign productions in Estonia). The need for the new studio was also one of the topics where the opinions of the interviewees diverged most often. One group of interviewees argued that the new studio would 
be an important prerequisite for strengthening the sector's capacity. The others were again sceptical about the cost-effectiveness of the related investments. Even if the Estonian film production sector would attract more foreign productions to Estonia, the numbers of local professionals to cover the whole flow of film production are still limited - which would question the rationale behind developing new expensive infrastructure.

Also, the dependence on public funding could be seen to hinder the clustering of Estonian film sector. In most cases, the Estonian film production activities rely only on public sector funds. There is no indication that the volume of state funding could increase in the (near) future, this in turn limits unavoidably the potential to increase the volumes of the (local) audiences.

If about two or three motion pictures are produced in a year here, then they just disappear into the rest of the mass and well, you must train a person to watch locally produced films in the same way. If we were to produce 8 films a year for 10 years, then people would sort of learn and grow to watch these films. [2]

There are only a few examples of involving private sector finances (e.g. loans, investments, sponsorships). This can be explained to an extent by the limited financial competencies of film sector entrepreneurs. But this is also due to the small size of the local market and other limitations to the local demand described above that may curb the motivations of potential investors. Also, Estonian production companies tend to be focused on producing art house films rather than targeting either mass audiences with more entertainment oriented content or producing genre films (for instance horror, sci-fi) for the long tail of global niche audiences.

When it comes to financial capabilities then the overall ability and openness of film companies to take loans to support their development goals is rather modest. On the one hand, the entrepreneurs consider it too risky and, on the other, the banks are not eager to lend to markets that are generally perceived to be rather unpredictable for all the aforementioned reasons.

The study also revealed that the Estonian film sector significantly lacks ties with other sectors. When it comes to other fields of art then strong and effective partnerships have been built between film and the performing arts - theatre and music. The interviewees praised the cooperation with actors and musicians and their umbrella organisations that have helped to formalise clear standards, for instance, for remuneration among other aspects. The links with other sectors and industries are substantially weaker. However, closer cooperation with other sectors, especially with the information and communication technology (ICT) sector, was seen as an opportunity by the majority of the interviewees. When it comes to such potentially interdisciplinary cooperation then one of the hindrances is also the lack of cooperation with research and development institutions. None of the respondents in this study indicated that their company is cooperating with research institutions.

One of the deterrents to clustering is the relative weakness of the film-sector's umbrella organisations - an aspect influencing its inherent coherence. There are multiple associations and unions that associate themselves with the film sector in Estonia, but many of them are rather inactive. The interviewees argued that the umbrella organisations are too fragmented and do not speak with one 'voice'. According to interviewees these are also of little use: they are especially weak in organising joint cross-border activities, similarly in finding partners and fostering cooperation projects. Still, one can observe several positive developments in the recent years. While the multiplicity of umbrella organisations continues to keep the sector fragmented, new institutions have emerged that have facilitated new forms of joint international operations. The establishment of Estonian Digital Centre and Estonian Film Commission both 
increase the reputation of Estonia as a

location for film production.

\section{Development alternatives for Estonian film cluster}

Here we introduce the possible development alternatives for the Estonian film cluster that were derived from the synthesis analysis of Porter's four factors. We start by describing the two factors, which formed the basis for the construction of the development alternatives. The first factor relates to the diversity of actors and fields related to the cluster. On the one hand, several interviewees expressed their doubts about strengthening cooperation with other industries. Some of the interviewees even questioned the need for strengthening the cooperation within the audio-visual sector as film producers and television producers or film producers and post-production companies are supposedly different kind of actors with varying development needs. In order to find solutions to the development problems bigger fragmentation was seen as a solution. Quoting an interviewee:

For me it is very important, for many film makers it is very important to draw a thick red line between film producers and television producers. The production specificity is too different. So, if we have film producers then only film producers. The associations for directors and screen writers pronounced also that they don't want to get involved with TV work since the work specificity is different. [14]

On the other hand, the cooperation with other fields was seen as an opportunity for strengthening the capacity and competitiveness of the film sector. Collaboration was seen with the fields that offer synergy and amplification for film sector: ICTs, games and media sector were mentioned most often.

I can see that there are many elements that create synergy between companies. So let us take production companies, for example, and animation studios and let us say sound studios, and then, that they are together a group that produces material for TV and cinemas. Then there is the game industry and the Internet industry that also use people with similar skills. [8]

The second factor relates to the infrastructure and environment conditions necessary for cluster development. The need for the development of the infrastructure and environment that supports the development of the film sector was commonly understood and valued, although the choices for that were seen differently. One group of interviewees clearly favoured the development of physical infrastructure, including the film pavilion. For them the lack of necessary infrastructure was a barrier to the film sector's development and the establishment of a physical edifice with contemporary technology would bring growth opportunities for the film sector. The other group of interviewees consisted of those who, although they saw the need for the development of a new production facility, doubted the cost-effectiveness of the investments. This was explained with the rapidly changing technology and the low demand for these technologies in real terms.

I am with those that think that we don't need to build (a studio) here. This is such a bit naive dream. Close to us similar things have been built, also Russians have built their own. But many I hear are staying empty. This is quite like: "let's try, let's invest!" But this is too big to simply try out. I don't understand where is the enthusiasm of these people coming from? How are they going to staff all these...? /.../ And long will the payback period be for this investment? [6]

On the basis of these two factors (axes) the study identified four development alternatives for Estonian film cluster (see also Figure 2). The following describes the principal characteristics of each of the four alternatives. 


\section{FACTOR \\ CONDITIONS}

+ educated and

competent human

resources

+ concentration to

the city centre

+ accessibility of technology

+ state financing system

+ Tallinn University Baltic Film and Media School

+/- Estonian Digital Centre, Estonian Film Commission

- lack of competences in marketing, financial and juridical fields

- dependency of public sector financing

- lack of private investors

- missing film pavilion

- fragmented and non-active representative organisations

- lack of specific support schemes, e.g. no tax exemptions for film

\section{FIRM STRATEGY, STRUCTURE AND RIVALRY}

+ orientation towards internationalisation

+ tight cooperation between enterprises

+ cooperation and competition go hand in hand

- small and weak enterprises

- project based activities predominantly

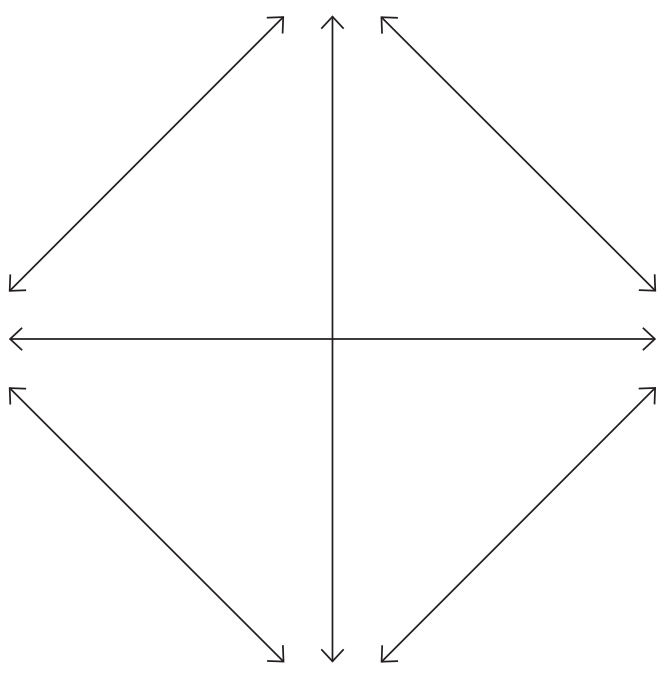

DEMAND

+ development of cross-media

- small home market

- missing Estonian wide cinema network

- small international reputation

\section{RELATED AND SUPPORTING INDUSTRIES}

+ tight cooperation with creative industries (performing arts)

+ television as a possible output channel

- weak cooperation with ICT enterprises (for the development of production technics and technologies)

FIGURE 1. The strengths and weaknesses of the competitiveness of the Estonian film cluster based on Porter's diamond model. 
Alternative 1 - Studio based film cluster for film companies - is a cluster which encompasses film sector companies with dedicated production facility. It aims to enhance cooperation efficiency among film sector companies and improve the quality of film production and services. The actors in the cluster cover the whole flow of the film production process, from production to distribution. The majority of the film sector companies move to the new facility that is developed around a new large-scale studio together with supporting services, including renting equipment, lightening, casting services, sound engineering, post-production services, distribution, etc. Alternative 2 - Film with partners around the studio - is a cluster which has similarly developed next to the new production facility, but it encompasses not only film sector enterprises, but also companies from several other fields such as online media, ICTs, television. The aim of the cluster would be to enhance international competitiveness of the whole audio-visual sector in Estonia and the main potential is seen to emerge from the synergy of different industries located together. Alternative 3 - Cloud cluster for film companies - again encompasses solely film sector companies, but is a virtual-social network without a concentrating production facility. It proceeds from an understanding that in the context of limited resources the main effort for strengthening Estonian film cluster capacity is to invest into improving the information exchange, joint marketing and export activities instead of investing into developing new infrastructures. Alternative 4 - Mixed community in the cloud - is also a network-based cluster, but it encompasses several other fields besides film sector. It aims to make use of the competencies and synergies of different fields to support the innovation in the audio-visual sector.

To summarise, all of the four alternatives for the Estonian film cluster are based on the enhancement of collaboration in the film sector, but differ from the range of actors involved in that cooperation. The fundamental question is whether to stay within the frame of the film sector (together with post-production and distribution) or to expand and involve actors from other industries. Another fundamental choice is based on the question of whether there is the need for a built production facility that integrates different actors or if the virtual network is enough to strengthen the cooperation within the film sector as well as between film and other sectors.

\section{DISCUSSION AND POLICY SUGGESTIONS}

The purpose of this study was to evaluate the ongoing clustering of film enterprises in Tallinn, and based on this, to assess the prospects for the further development of a cluster. To conclude the results, it can be suggested that the AV-cluster formation in Tallinn is not going to slow down. The Estonian film industry can be characterised by close horizontal and vertical relationships between the enterprises and creative individuals and also by their further readiness to cooperate. Collaboration and competition go hand in hand: enterprises competing for external funding at one moment could be cooperating on another project the next moment. Most of the entrepreneurs in the Estonian film industry also believe that they can benefit from a cluster in several ways. Entrepreneurs felt that the cluster could play an important role in improving business cooperation further and enhancing communication among industry fractions. This could also help gain better access to foreign funding and/or to enable work on larger foreign projects. These aspirations are especially pronounced in the answers provided by the younger entrepreneurs in the industry. This may be due to their relatively smaller involvement in the social networks of the industry and the slightly more marginal position of their enterprises in the dynamics of the audiovisual industry so far. The further organic development of the cluster is supported by the fact that enterprises have already agglomerated in the centre of Tallinn and in the nearby district of Põhja-Tallinn (northern part of the city). The majority of the interviewees expressed a need for better production 


\section{Developed physical}

environment

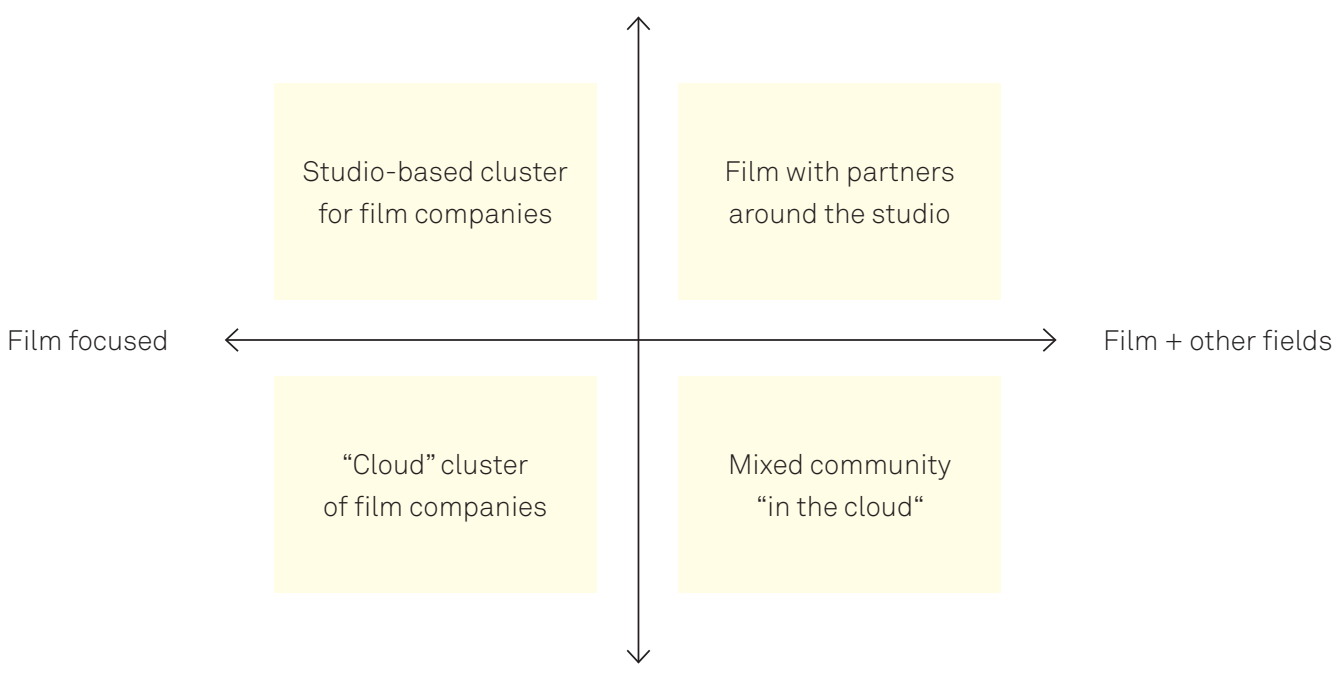

Virtual social network

FIGURE 2. Development alternatives for Estonian film cluster. 
facilities (studios and post-production facilities) and were motivated to save on related expenses by converging around the potential new facility. This also indicated where the common cluster infrastructure should be located (regardless of how largeor small-scale the plans are). The interviewees expressed uniformly that to construct this infrastructure outside of Tallinn was not an acceptable solution. All in all, we may conclude that the evolving Estonian film cluster has several traits common to contemporary (creative) clusters, including the dense, but varied cooperation pattern, the dominance of the co-opetition model and spatial agglomeration to a relatively small area. The co-opetition model also refers to strong interdependences between the film sector actors as well as to the increasing complexity of value chains and business models - the traits that are increasingly and especially common in creative industries. The business practices of the Estonian film sector actors also coincide with the contemporary global trends in the cultural labour markets, i.e. the relative individuation, the related abundance of micro-actors (entrepreneurs, micro-firms), the dominance of project-based and parttime work, the coordination of the execution of such project-based work based on the evolving mutual trust between multiple micro-sized partners, etc.

Among Porter's clustering factors the main hindering factors of the Estonian film cluster relate to the demand conditions. The most important factor that limits the development of a cluster is the small size of the home market. A strong home market is generally considered to be a prerequisite for a strong cluster. The cinema network in Estonia is increasingly lacking and VOD services are underdeveloped. Export potential is hindered by the fact that little is known about the Estonian film industry internationally; another obstacle is the intensity of international competition where the 'winners' are often countries with a clear policy, a larger home market and a large volume of subsidies for film industry provided by the public sector. At that, production companies and post-producers should be differentiated; the respondents from postproduction companies admitted that demand for their services is already great and increasing. This is also confirmed by market statistics - profit margins and the general productivity of post-production companies are among the highest in the audiovisual sector.

Insufficient public funding and almost non-existent private investments negatively influence the further development of a cluster. There are only very few examples of cases where private funding was successfully involved in a project. Due to the aforementioned factors, several respondents doubted whether creating a new production facility and developing a cluster around that would be economically feasible. As the excessively high rental prices for office spaces as well as the high costs of equipment were feared, entrepreneurs were very careful about making commitments. Some of the entrepreneurs were therefore hesitant, expressing that if the cluster succeeded, they would also consider joining. Thus, the critical importance of a cluster developer emerges; the developer would need to develop a dialogue with such enterprises in order to create a common vision and a feasible strategy for the cluster - i.e., to establish trust, which is generally perceived as one of the key features of creative clusters.

On the one hand, the relative weakness of the enterprises in this industry (conditioned by shortcomings in sales, marketing, financing and legal skills) is a problem for the evolution of the cluster. Enterprises that are weak are also incapable of supporting each other properly. On the other hand, the weakness of enterprises is an important motivator that actually directs enterprises towards clustering. Weaker enterprises need and seek out greater support from their environment. The influence of the weakness and fragmentation of the umbrella organisations of the film industry on further cluster development is similarly paradoxical. On the one hand, the weakness and fragmentation of representative organizations is inevitably caused by the relatively 
insufficient central coordination of this domain. On the other hand, greater need for integration provides a motivation for more intense clustering.

The development of any dynamically operating cluster generally also assumes the inclusion of research and development institutions to strengthen its potential for innovation. However, currently, the enterprises of the Estonian audiovisual production sector do not have much experience in cooperating with research and development institutions or the information and communication technology sector, which could provide the main possibilities for innovation. But it is important to emphasise that the interviewees expressed the desire to cooperate with other sectors, especially with the field of ICT. Yet, it is also clear that launching research and development activities is inevitably a slow process because it also implies the existence of available resources that small enterprises in the AV sector generally lack.

Based on the aforementioned factors, four potential alternatives for the further development of the cluster were formed: 1) a studio-centred cluster for film companies; 2) a studio-centred cluster that integrates film companies with other audiovisual and online media and enterprises in the ICT sector; 3) a film-centred virtual cluster; 4) a virtual cluster that integrates film companies with other audiovisual and online media and enterprises in the ICT sector. As a way of providing feedback, we described these alternatives to the enterprises during a separate round table session (resembling a focus group). This round table discussion supplemented the results of the earlier interviews in several aspects and further confirmed the developmental tendencies of the cluster. Just as the majority of film entrepreneurs interviewed preferred a cluster that would be formed on a wider basis to include entities from other industries (e.g. ICT), so did the participants of the round-table favour a more inclusive cluster. When some of the entrepreneurs expressed doubt about the necessity for a new cluster facility, then the roundta- ble also emphasized the need to establish clear goals and focus for the cluster as well as the importance of finding a critical mass of participants for the cluster. Participants agreed that the functions and form of the infrastructure need further, thorough discussions.

Based on our analysis, we propose that the activities that support the further development of a cluster should be conducted by the enterprises as well as the public sector and that the central government and local city authorities of Tallinn could contribute with appropriate policy measures and support schemes. As far as the activity of enterprises is concerned, three important aspects for the development of the cluster can be pointed out that need greater attention than others. Firstly, developing a vision and strategy for the cluster. The industry must reach a greater consensus on the development of the cluster and this topic must be discussed more frequently and consistently.

Another goal for the enterprises is ascertaining the needs of the infrastructure of the cluster. In order to make large-scale investments into infrastructure, it is important to establish certainty that the cluster has a critical mass of participants and the participants of the cluster have a common vision for the development of the industry, and to acquire a deeper understanding of the possible future trends of the film industry (i.e. technological development and international demand). Also, the pricing policy of services provided by the cluster must be as transparent as possible, clearly predictable and stable. There are plenty of examples from around the world of the clusters of different industries where the participants are not located in the same environment but are united by the cluster's economic ties, common events, communication channels/ platforms, joint activities, etc. The Internet increasingly facilitates these forms of cooperation and its 'social-network-market-like' dynamics that increasingly include various 'outer layers' of interested individuals, associated enterprises, semi-professional supporters, dedicated fans, etc. At the same time, different cluster concepts emphasize 
that the physical proximity strengthens cooperation and fosters innovation; therefore, it is also important for the further development of the cluster that a (the more active) subsection of the local film industry was located in the same environment. Based on the results of the study that younger enterprises considered the cluster to benefit them the most, it would be rational to first consider the needs and interests of these entrepreneurs when developing the cluster facilities.

A third area for development could be to establish cooperation with closely connected industries. Taking into account the influence of technology development on the production as well as consumption of audiovisual content, there is a good reason to expect a rather organic emergence of a wider and more inclusive cluster. Enterprises in the AV industry should primarily try to include enterprises from the ICT sector in their cluster. Keeping in mind that the Estonian ICT industry has a good international reputation, linking the enterprises in the AV industry with the enterprises in the ICT industry could provide an important impetus for the development of the AV cluster. Internationally, the integration of AV and ICT industries in specifically dedicated new clusters is a common rather than a rare phenomenon, often resulting in new methods to engage the audience and to distribute content. Also, cooperating with ICT industry could help alleviate (at least to a certain extent) the problem of limited demand for Estonian audiovisual content by the development of new access platforms and cross-media solutions. Lastly, specifically for the film sector it would be good to overcome its occasional strict opposition to TV content production. As our study demonstrated the more successful enterprises of the sector work already across genre or medium boundaries (main source of income are commercials and other TV content) and as the policy tendencies indicate (European Commission 2013) the convergence within the field of audiovisual content production in regard to not only distribution platforms and strategies, but also production proc- esses and budgets, will be quickening rather than slowing down.

Considering the small size of the enterprises in the audiovisual industry and their modest capitalisation, it can be suggested that, in addition to contributions from private investors, it is time to consider how the public sector could contribute towards the development of a possible infrastructure for the cluster. At the same time, there are other policy measures that the public sector could implement to support the strengthening of the enterprises in this sector as well as channel the further formation of the cluster. Based on our analysis, we suggest supporting the development of the AV industry more systematically as a complete ecosystem. AV enterprises can only develop in conjunction with their environment (increasing demand - including the development of the scope of the cinema network and VOD; the diversification of funding possibilities, including the further development of funding schemes [e.g. guarantees for private investors]). Without the continuous development of the ecosystem, there is no reason to expect that individual companies will evolve in leaps and bounds. A competitive cluster is based on the development of its enterprises and their business environment.

\section{ACKNOWLEDGMENT}

The preparation of the article was supported by the European Union through its European Regional Development Fund (Centre of Excellence in Cultural Theory) as well as by research grant ERMOS79 financed by the Estonian Science Foundation and co-funded by Marie Curie Actions. 


\section{REFERENCES}

Atkinson, R.; Flint, J. 2004. 'Snowball sampling'. - M. S. Lewis-Beck, A. Bryman, T. F. Liao (eds.), Encyclopedia of Social Science Research Methods, Vol 1. Thousand Oaks: Sage, 1044-1045.

Banks, M.; Lovatt A.; O’Connor J.; Raffo, C. 2000. 'Risk and trust in the cultural industries'. - Geoforum, 31, 453-464.

Boix, R.; Lazzeretti L.; Hervàs J. L.; Miguel B. 2011. 'Creative clusters in Europe: a microdata approach'. Paper presented at the European Congress of Regional Science Association International, ERSA, Barcelona. Burmeister, K.; Neef, A.; Albert, B.; Glockner, H. 2002. Zukunftsforschung und Unternehmen. Praxis, Methoden, Perspektiven. Essen: Z punkt GmbH Büro für Zukunftsgestaltung.

Castells, M. 1996. The Rise of the Network Society: The Information Age: Economy, Society, and Culture. Oxford: Blackwell.

Davis, C. H.; Creutzberg, T.; Arthurs D. 2009. 'Applying an innovation cluster framework to a creative industry: The case of screen-based media in Ontario.' Innovation: Management, Policy \& Practice, 11, 201-214. Deuze, M. 2007. Media Work. Cambridge: Polity. Evans, G. 2009a. 'Creative cities, creative spaces and urban policy.' - Urban Studies, 45, 5\&6, 1003-1040. Evans, G. 2009 b. 'From cultural quarters to creative clusters - creative spaces in the new city economy.' - Legner, M.; Ponzini, D. (eds.), The Sustainability and Development of Cultural Quarters: International Perspectives. Stockholm: Institute of Urban History, 32-59.

European Commission 2013. Preparing for a Fully Converged Audiovisual World: Growth, Creation and Values. Green Paper, COM (2013), 231.

Gill, R. 2007. Technobohemians or the New Cybertariat? New Media Work in Amsterdam a Decade after the Web. Amsterdam: Institute of Network Cultures.

Gordon, I. R; McCann, P. 2000. 'Industrial clusters: complexes, agglomerations and/or social networks'. - Urban Studies, 37, 513-533.

Granovetter, M. 1985. 'Economic action and social structure: the problem of embeddedness'. - American Journal of Sociology, 91, 481-510.

Harrison, B. 1992. 'Industrial districts: old wine in new bottles?' - Regional Studies, 26, 469-483.

Heijden, K. van der 1996. Scenarios: The Art of Strategic Conversation. Chichester: Wiley.

Hoover, E. M. 1948. The Location of Economic Activity. New York: McGraw-Hill.

Hsieh, H.-F.; Shannon, S. E. 2005. 'Three approaches to qualitative content analysis'. - Qualitative Health

Research, 15, 1277-1288.

Laherand, M.-L. 2008. Kvalitatiivne uurimisviis. Tallinn. Lazzeretti L.; Boix, R.; Capone, F. 2008. Do Creative Industries Xluster? Mapping Creative Local Production Systems in Italy and Spain. Working Paper 08.05. Departament d'Economia Aplicada, Universitat Autònoma de Barcelona, Barcelona.

Lorenzen, M. 2007. Creative Encounters in the Film Industry: Content, Cost, Chance, and Collection, Creative Encounters Working Papers No. 3. Copenhagen: Copenhagen Business School.

Marshall, A. 1925. Principles of Economics. 8th edn. London: Macmillan Press.

Mccann, P. 1995. 'Rethinking the economics of location and agglomeration'. - Urban Studies, 32, 563-577.

Moses, L. 1958. 'Location and the theory of production': - Quarterly Journal of Economics, 78, 259-272.

Porter, M. E. 1990. The Competitive Advantage of Nations. London: Macmillan Press.

Porter, M. E. 1998. 'Clusters and the new economic competition: - Harvard Business Review, 76, 77-90. Porter, M. E. 2001. 'The competitive advantage of nations. - Harvard Business Review, March-April, 73-93.
Potts, J.; Cunningham, S.; Hartley, J.; Ormerod, P. 2008. 'Social network markets: A new definition of the creative industries'. - Journal of Cultural Economy, 32, 167-185.

Potts, J.; Keane, M. 2011. 'Creative clusters and innovation'. - Potts, J., Creative Industries and Economic Evolution. Chelthenham: Edward Elgar, 152-161.

Pratt, A. 2004. 'Creative clusters: towards the governance of the creative industries production system?' Media International Australia 112, 50-66.

Roodhouse, S. 2006. Cultural Quarters: Principles and Practice. Bristol: Intellect.

Sölvell, Ö.; Lindqvist, G.; Ketels, C. 2003. The Cluster Initiative Greenbook. Stockholm: Ivory Tower.

Tafel-Viia, K.; Viia, A.; Terk, E.; Ibrus, I.; Lassur, G. 2011. Väike-ja mikroloomeettevõtete arengutsükkel. Tallinn:

Tallinn University's Estonian Institute for Futures Studies.

van Dijk, J. 2006. The Network Society. 2nd edn. London: Sage.

Wirtz, B. W. 2001. 'Reconfiguring of value chains in converging media and communications markets.' Long Range Planning, 34, 489-506. 